\title{
Novel $\left(\mathrm{NH}_{4}\right)_{4}\left[\mathrm{NiMo}_{6} \mathrm{O}_{24} \mathrm{H}_{6}\right] \cdot 5 \mathrm{H}_{2} \mathrm{O}-\mathrm{TiO}_{2}$ composite system: Photo- oxidation of toluene under UV and sunlight-type illumination
}

\author{
Mario J. Muñoz-Batista ${ }^{\mathrm{a}, \mathrm{b}}$, Guillermo R. Bertolini ${ }^{\mathrm{c}}$, Carmen I. Cabello ${ }^{\mathrm{c}}$, Rafael Luque ${ }^{\mathrm{b}}$, \\ Enrique Rodríguez-Castellón ${ }^{\mathrm{d}}$, Anna Kubacka ${ }^{\mathrm{a}, *}$, Marcos Fernández-García ${ }^{\mathrm{a}, *}$ \\ ${ }^{a}$ Instituto de Catálisis y Petroleoquímica, CSIC, C/ Marie Curie, 2, 28049 Madrid, Spain \\ b Departamento de Química Orgánica, Universidad de Córdoba, Edif. Marie Curie, Ctra Nnal IV-A, Km 396, E14014, Córdoba, Spain \\ “Centro de Investigación y Desarrollo en Ciencias Aplicadas Dr. J. Ronco" CINDECA-CCT La Plata-CONICET-UNLP, Calle 47 № 257, 1900 La Plata, Argentina \\ d Departamento de Química Inorgánica (unidad asociada al ICP-CSIC), Facultad de Ciencias, Universidad de Málaga, 29071 Málaga, Spain
}

\section{A R T I C L E I N F O}

\section{Keywords:}

NiMo Anderson

Anatase

UV

Sunlight

Toluene

Quantum efficiency

\begin{abstract}
A B S T R A C T
A series of composite materials based on titania and growing quantities of the $\left(\mathrm{NH}_{4}\right)_{4}\left[\mathrm{NiMo}_{6} \mathrm{O}_{24} \mathrm{H}_{6}\right] \cdot 5 \mathrm{H}_{2} \mathrm{O}$ heteropolyacid $\left(\mathrm{NiMo}_{6} \mathrm{HPA}\right)$ was tested in the gas-phase toluene photo-oxidation reaction. Materials were characterized with the help of chemical analysis, X-ray diffraction, porosimetry, electron transmission and scanning microscopies, as well as X-ray photoelectron and UV-visible diffuse-reflectance spectroscopies. Photoactivity performance was assessed under UV and sunlight-type illumination conditions through the calculation of the true quantum efficiency to measure activity as well as the analysis of the selectivity of the reaction. The composite system having a $3 \mathrm{wt}$. \% of the $\mathrm{NiMo}_{6}$ component presents improved performance with respect to well defined titania references (parent nanosized anatase or P25) under all illumination conditions tested. The characterization of the solids indicates that the $\mathrm{NiMo}_{6}$ component supported on titania suffers a significant modification of its physico-chemical properties as a function of the loading of the composite system. Such modification appears as a consequence of the interface interaction between the components of the composite system. An electron paramagnetic resonance study of the radical species formed under illumination shows that charge handling through the $\mathrm{NiMo}_{6}-\mathrm{TiO}_{2}$ interface controls the photo-catalytic properties.
\end{abstract}

\section{Introduction}

Heterogeneous photocatalysis is a relatively well established technology based in the use of semiconductors and light to create charge carrier species able to transform chemical molecules [1,2]. There are a number of photocatalytic active semiconductors but the search for new ones is an open field. In this respect, one family of materials with interest corresponds to the Polyoxometallates (POMs). POMs correspond to a wide class of functional materials consisting on nanoscale transition metal oxide clusters [3]. The most explored POMs are the heteropolyacids (HPAs). These materials are customarily classified starting from the unit "parent" polycations, being the Keggin $\left(\mathrm{XM}_{12} \mathrm{O}_{40}{ }^{\mathrm{n}-}\right)$, Dawson $\left(\mathrm{X}_{2} \mathrm{M}_{18} \mathrm{O}_{62}{ }^{\mathrm{n}-}\right)$, Lindquist $\left(\mathrm{M}_{6} \mathrm{O}_{19}{ }^{\mathrm{n}-}\right)$, and Anderson $\left(\mathrm{XM}_{6} \mathrm{O}_{24}{ }^{\mathrm{n}-}\right)$ structures among the most utilized as functional materials in chemistry [3,4]. Structurally, the group $\left[\mathrm{XMo}_{6} \mathrm{O}_{24} \mathrm{H}_{6}\right]$ consists of a packing of six $\mathrm{Mo}_{6}$ octahedron around an $\mathrm{XO}_{6}$ polyhedron in a planar symmetry $\mathrm{D}_{3 \mathrm{~d}}$ configuration. The central octahedron can locate heteroatoms of ionic radius between 0.5 and $0.7 \mathrm{~nm}$, opening a pathway to prepare a wide variety of compounds and phases. In our case, The POM contains $\mathrm{Ni}(\mathrm{II})$ as heteroatom in the centre of an octahedron whose vertices are $(\mathrm{OH})$ groups that, in turn, are shared with six octahedrons $\mathrm{Mo}(\mathrm{VI}) \mathrm{O}_{6}$. Heteropolymetalates with Anderson structure are not strongly acidic and present significant stability for catalytic applications, particularly, for those materials containing POMs and supported on high surface area oxides [4-6].

The utilization of POMs together with titanium oxide appears as the most successful combination for their application in the photocatalytic field. The usefulness of such composite materials is based in a number of potential interesting facts. First of all, such combination introduces new acid/base and cationic functionalities to a titania support, expanding or modifying the chemical potential of the reference oxide in photocatalysis. Second, the heteropolyacid can profit from the high surface area of the titania and therefore presents a significantly higher surface area to the reactant atmosphere. Finally, a significant number of POMs has lower band gap energies than titania, allowing the fruitful use of visible photons [4-10]. Interestingly, although Keggin and

\footnotetext{
* Corresponding authors.

E-mail addresses: ak@icp.csic.es (A. Kubacka),mfg@icp.csic.es (M. Fernández-García).
} 
Dawson HPAs have been used in photocatalysis, those having Anderson structures are significantly less employed [7]. In particular, we are not aware of any utilization of the $\left(\mathrm{NH}_{4}\right)_{4}\left[\mathrm{NiMo}_{6} \mathrm{O}_{24} \mathrm{H}_{6}\right] \cdot 5 \mathrm{H}_{2} \mathrm{O}$ nanometric cluster in photocatalysis.

As we will show here, the composite system joining $\mathrm{NiMo}_{6}$ with a high surface area anatase renders highly active systems under UV, visible, and sunlight-type illumination conditions in gas-phase toluene photo-oxidation. This reaction is a typical benchmark in the field as toluene is a though pollutant, present in urban atmospheres and rather difficult to be photo-oxidized $[11,12]$. Considering the green chemistry rules, it would be interesting to photo-oxidize toluene (as well as other pollutants) to produce chemical molecules with potential industrial interest. In the case of toluene, benzaldehyde and benzoic acid are industrially appealing products. In fact, benzoic acid is industrially obtained from toluene using (thermal-driven) Co-based catalysts [13].

To provide a rigorous ground for analyzing the photo-activity of the materials, we calculated the true quantum efficiency of the chemical process using experimental and computational procedures previously presented [14]. Significant variation of the activity is observed as a function of the POM content in the materials obtained by its combination with a dominant anatase phase. Additionally, changes in the selectivity of the reaction were observed, denoting the potential influence of the $\mathrm{NiMo}_{6}$ clusters in the surface chemistry of the anatase structure. The work also presents a multitechnique physico-chemical characterization of the materials using X-ray diffraction, UV-visible and $\mathrm{X}$-ray photoelectron spectroscopies together with microscopy and porosimetry techniques. The characterization study describes the electronic and structural effects of the materials and attempts a rationalization of the catalytic output of the composite catalysts as a function of their chemical composition. Importantly, the $\mathrm{NiMo}_{6}-\mathrm{TiO}_{2}$ composite system has not been tested previously (to our knowledge) in the photocatalysis field and the results reported here provide evidence of its goodness and/or adequacy for photo-oxidizing toluene under all illumination conditions tested. The improved performance with respect to well defined titania reference systems was further corroborated with an electron paramagnetic resonance of radical species produced under irradiation conditions. The improvement with respect to the titania references indicates the potential utility of such composite in a broad number of photo-catalytic reactions concerning organic molecules (pollutants or not) degradation and/or transformation processes. This occurs under UV but also under Sunlight-type illumination, indicating the suitability of the system for solar-assisted processes.

\section{Experimental}

\subsection{Preparation of the samples}

The general synthesis of the ammoniacal salt of the Anderson-like structure phase $\left(\mathrm{NH}_{4}\right)_{4}\left[\mathrm{NiMo}_{6} \mathrm{O}_{24} \mathrm{H}_{6}\right] \cdot 5 \mathrm{H}_{2} \mathrm{O}$ is carried out by precipitation at room temperature, from the aqueous solutions of the respective salts of the metal ions, following recipes described elsewhere $[15,16]$. Briefly, the synthesis essentially consists on the mixture at room temperature of aqueous solutions of $\left(\mathrm{NH}_{4}\right)_{6}\left[\mathrm{Mo}_{7} \mathrm{O}_{24}\right] \cdot 4 \mathrm{H}_{2} \mathrm{O}$ and $\mathrm{NiCl}_{2} \cdot 6 \mathrm{H}_{2} \mathrm{O}$ in stoichiometric proportions under stirring. Precipitation is carried out in a slightly ammoniacal medium, adjusting the $\mathrm{pH}$ in the range $5-6$, in which the species is stable. Once the precipitate is obtained, the filtrate is profusely washed with distilled water and dried at room temperature. The corresponding reference material is called NiMo, and was characterized by XRD, IR and UV-visible as described previously $[15,16]$.

Titania was prepared using a microemulsion method by addition of titanium tetraisopropoxide to an inverse emulsion containing an aqueous solution dispersed in $n$-heptane, using Triton X-100 (Aldrich) as surfactant and hexanol as cosurfactant. Total cation content of the aqueous solution is $0.5 \mathrm{M}$. Water/(Ti) and water/surfactant molar ratios were, respectively, 111 and 18 for all samples. The resulting mixture was stirred for $24 \mathrm{~h}$, centrifuged, decanted, rinsed with methanol and dried at $100{ }^{\circ} \mathrm{C}$ overnight. Following the microemulsion preparation method, the amorphous powder was calcined for $2 \mathrm{~h}$ at $600{ }^{\circ} \mathrm{C}$ [17]. The corresponding reference material is called Ti.

The composite catalysts were obtained by wetness impregnation (ca. $0.6 \mathrm{~mL} \mathrm{~g}^{-1}$ ) of a $\mathrm{NiMo}_{6}$ ethanol/toluene solution to the titania support. Drying overnight at $100{ }^{\circ} \mathrm{C}$ was carried out. Catalysts were impregnated with quantities of $\mathrm{NiMo}_{6}$ in the 1 to $4 \mathrm{wt}$. \% interval. Catalysts were named $\mathrm{xNiMo} / \mathrm{Ti}$ where $\mathrm{x}$ denotes the weight percentage of $\mathrm{NiMo}_{6}$. The reference samples are called Ti (Titania) and NiMo (the pure $\mathrm{NiMo}_{6}$ compound).

\subsection{Characterization techniques}

Chemical composition of the solids was measured using total reflection x-ray fluorescence (Bruker - S2 PicoFox TXRF Spectrometer). The Brunauer-Emmett-Teller (BET) surface areas and average pore volumes and sizes were measured by nitrogen physisorption (Micromeritics ASAP 2010). XRD profiles were obtained with a Seifert D-500 diffractometer using Ni-filtered $\mathrm{Cu}$ K $\alpha$ radiation with a $0.02^{\circ}$ step and fitted using the Von Dreele approach to the Le Bail method [18]. Particle sizes and microstrain were measured with XRD using the Willianson-Hall formalism. UV-vis diffuse-reflectance spectroscopy experiments were performed on a Shimadzu UV2100 apparatus using nylon as a reference. XPS data were recorded on $4 \times 4 \mathrm{~mm}^{2}$ pellets, $0.5 \mathrm{~mm}$ thick, prepared by slightly pressing the powered materials which were outgassed in the prechamber of the instrument at room temperature up to a pressure $<2 \times 10^{-8}$ Torr remove chemisorbed water from their surfaces. The SPECS spectrometer main chamber, working at a pressure $<10^{-9}$ Torr, was equipped with a PHOIBOS 150 multichannel hemispherical electron analyzer with a dual X-ray source working with with $\mathrm{Al} \mathrm{Ka}(\mathrm{h} \nu=1486.6 \mathrm{eV})$ at $120 \mathrm{~W}, 20 \mathrm{~mA}$ using C $1 s$ as energy reference for adventitious carbon (284.6 eV). Transmission electron microscopy (TEM) and X-ray energy dispersive spectra (XEDS) were recorded on a JEOL $2100 \mathrm{~F}$ TEM/STEM microscope using a copper sample holder (Lacey / Carbon 200 Mesh, Copper (Cat. \# LC200-CU) from Electron Microscopy Science - emsdiasum). Scanning electron microscopy (SEM) was recorded in a JEOL JSM-7800 apparatus with Xray energy dispersive (XEDS) spectra taken at $20 \mathrm{KeV}$. Au/Pd coating was employed to analyze the samples (SC7640 Instrument working at a

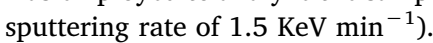

The electron paramagnetic resonance (EPR) measurements were carried out with a Bruker ER200D spectrometer operating in the X-band and calibrated with a DPPH standard. For the 5,5-dimethyl-1-pyrroline $\mathrm{N}$-oxide (DMPO) spin trapping EPR experiments, the samples were suspended in water (at a concentration of $0.6 \mathrm{~g} \mathrm{~L}^{-1}$ ) and were sonicated for $4 \mathrm{~min}$ A solution $(0.01 \mathrm{M}$ ) of DMPO spin trap (supplied by Sigma) was prepared and kept on ice during the whole set of experiments. Bidistilled water (Elix-10) was employed for these preparations. $100 \mu \mathrm{L}$ of the solid suspension and $100 \mu \mathrm{L}$ of the DMPO solution were mixed into an EPR flat quartz cell under atmospheric air and irradiated at different times, through a spectroscopic Pyrex glass filter with a cut-off at ca. $220 \mathrm{~nm}$, with light excitation source(s) identical to that employed for the catalytic tests, being then immediately transferred to the spectrometer cavity for EPR analysis. A small radical concentration decay (of ca. $5 \%$ on average) was observed in the dark during the course of spectrum recording. The EPR spectra were obtained at $25{ }^{\circ} \mathrm{C}$ at ca. $9.75 \mathrm{GHz}$ microwave frequency, $19.5 \mathrm{~mW}$ microwave power, $100 \mathrm{kHz}$ modulation frequency, $1 \mathrm{G}$ modulation amplitude and $2 \times 10^{5}$ spectrometer gain. No significant signal saturation was observed in those conditions. Blank experiments were also performed over mixtures of $100 \mu \mathrm{L}$ of the DMPO solution and $100 \mu \mathrm{L}$ of water to check the absence of radical formation in the absence of solid under the employed conditions. 


\subsection{Photo-catalytic experiments}

Gas-phase photo-oxidation of toluene (Aldrich, spectroscopic grade) was carried in a continuous flow annular photoreactor using a set-up described elsewhere (see Figure S1 of the supporting information file) [19]. Activity and selectivity for the gas-phase photooxidation were tested in such continuous flow annular photoreactor containing ca. $40 \mathrm{mg}$ of photocatalyst as a thin layer coating on a pyrex tube. The corresponding amount of catalyst was suspended in $1 \mathrm{~mL}$ of ethanol, painted on a pyrex tube (cut-off at ca. $290 \mathrm{~nm}$ ), and dried at $25{ }^{\circ} \mathrm{C}$. The reacting mixture $\left(100 \mathrm{ml} \mathrm{min}^{-1}\right)$ was prepared by injecting toluene ( $\geq 99 \%$; Aldrich) into wet (ca. $75 \%$ relative humidity) air (20 vol. $\% \mathrm{O}_{2} /$ $\mathrm{N}_{2}$ ) flow before entering to the photoreactor, yielding an organic inlet concentration of ca. 700 ppmv. After flowing the mixture for $5 \mathrm{~h}$ (control test) in the dark, the catalyst was irradiated by four fluorescent UV or daylight lamps (UV: $6 \mathrm{~W}$; Sylvania F6 WBLT-65; Sunlight-type: $6 \mathrm{~W}$, Sylvania F6 W/D). Full details of the reactor geometry, lamp irradiance and optical behavior of the reactor components can be seen elsewhere [14]. Reaction rates were evaluated under pseudo-steadystate conditions, typically achieved after $5 \mathrm{~h}$ under illumination. The concentration of reactants and products was analyzed using an on-line gas chromatograph (Agilent GC 6890) equipped with HP-PLOT-Q/HPInnowax columns $(0.5 / 0.32 \mathrm{~mm}$ I.D. $\times 30 \mathrm{~m})$ and TCD /FID detectors. The two detectors are used in parallel and their output signals obtained using the same temperature programme ( $3 \mathrm{~min}$ at $40 \mathrm{C}$ followed by a 10 ${ }^{\circ} \mathrm{C} / \mathrm{min}$ ramp up to $240{ }^{\circ} \mathrm{C}$ ). Production of $\mathrm{CO}_{2}$ was followed with the TCD detector and toluene and organic products (only toluene and benzadehyde were detected) using the FID detector. Carbon balance above $95.5 \%$ was obtained in all experiments.

\subsection{Quantum efficiency calculation}

According to the IUPAC recommendation, the quantum efficiency was calculated as the ratio of the number of molecules reacting by the number of photon interacting with the sample (Eq. (1)) [20].

Q. E. $(\%)=100 \times \frac{\langle\mathrm{r}\rangle\left(\mathrm{mol} \mathrm{m}^{-2} \mathrm{~s}^{-1}\right)}{\left\langle e^{a, s}\right\rangle\left(\text { Einstein } \mathrm{m}^{-2} \mathrm{~s}^{-1}\right)}$

Where: $\mathrm{r}$ is the reaction rate normalized by catalytic area and $\left\langle e^{a, s}\right\rangle$ is the averaged local surface photon absorption rate. The first observable is defined in Eq. (2) and the latter is defined by Eq. (3) [21].

$\langle r\rangle=Q\left(\frac{\left\langle C_{0}\right\rangle-\langle C\rangle}{m S}\right)$

$e^{a, s}(\underline{\mathrm{x}})=q_{\text {sup }}(\underline{\mathrm{x}}) F_{A s}$

Where $C$ and $C_{0}$ are the concentration of toluene at times $\mathrm{t}$ and $\mathrm{t}=0, \mathrm{Q}$ is the total flow, $\mathrm{S}$ is the BET area $\left(\mathrm{m}^{2} \mathrm{~g}^{-1}\right)$ and the mass used $(\mathrm{m})$ in the reaction. Also, $F_{A s}$ is the fraction of light absorbed by the sample and $q_{\text {sup }}$ the radiation flux at each position ( $\underline{\mathrm{x}}=\mathrm{x}, \mathrm{y}, \mathrm{z}$ ) of the catalytic film. The surface average of the $e^{a, s}$ observable is used in Eq. (1). The $q_{\text {sup }}$ is obtained using Eq. (4).

$q_{\text {sup }}=\sqrt{{ }^{x} q^{2}+{ }^{y} q^{2}}$

Where

${ }^{\mathrm{x}} q={ }_{L_{A}}^{\mathrm{x}} q_{1}^{\uparrow}+{ }_{L_{B}}^{\mathrm{x}} q_{1}^{\uparrow}+{ }_{L_{A}}^{\mathrm{x}} q_{2}^{\downarrow}+{ }_{L_{B}}^{\mathrm{x}} q_{2}^{\downarrow}$

${ }^{y} q={ }_{L_{A}}^{\mathrm{y}} q_{1}^{+}+{ }_{L_{B}}^{\mathrm{y}} q_{1}^{+}+{ }_{L_{A}}^{\mathrm{y}} q_{2}^{-}+{ }_{L_{B}}^{\mathrm{y}} q_{2}^{-}$

${ }_{L_{A}}^{\mathrm{x}} q_{1}^{\uparrow},{ }_{L_{B}}^{\mathrm{x}} q_{1}^{\uparrow},{ }_{L_{A}}^{\mathrm{x}} q_{2}^{\downarrow},{ }_{L_{B}}^{\mathrm{x}} q_{2}^{\downarrow},{ }_{L_{A}}^{\mathrm{y}} q_{1}^{+},{ }_{L_{B}}^{\mathrm{y}} q_{1}^{+}$,

${ }_{L_{A}}^{\mathrm{y}} q_{2}^{-},{ }_{L_{B}}^{\mathrm{y}} q_{2}^{-}=f\left(q_{\mathrm{n}}, F_{T_{S}}, F_{T_{g}}, F_{R_{S}}, F_{R_{g}}\right)$

The OX and OY components (Eqs. (5)-(7); Figs. S1 and S3) of the $q_{\text {sup }}$ vector are obtained from boundary conditions corresponding to the

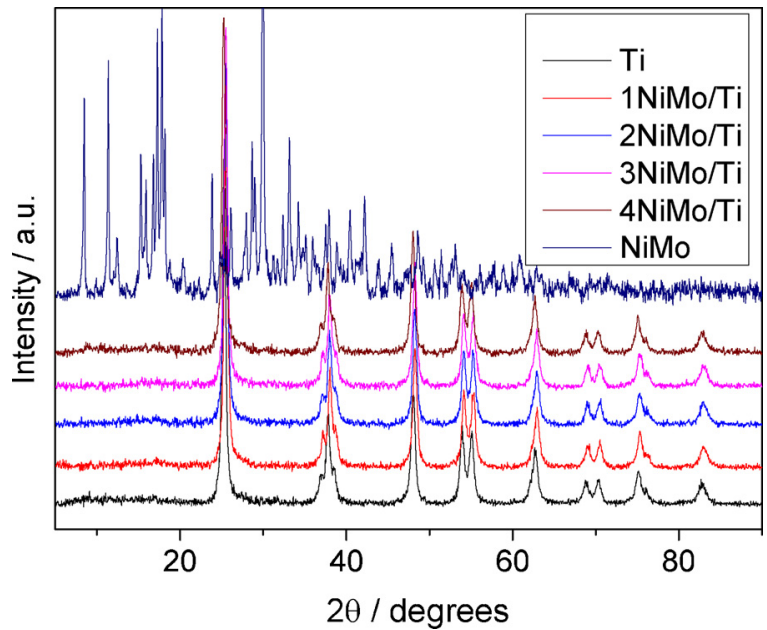

Fig. 1. XRD patterns of the samples.

Table 1

Anatase cell parameters and crystallite size for the samples. ${ }^{\text {a }}$

\begin{tabular}{llll}
\hline Sample & $\begin{array}{l}\mathrm{TiO}_{2} \\
\text { Size }(\mathrm{nm})\end{array}$ & \multicolumn{2}{l}{$\mathrm{TiO}_{2}$ anatase cell parameters $(\AA)$} \\
\cline { 3 - 4 } & & $a$ & $b$ \\
\hline $\mathrm{Ti}$ & 16.9 & 3.781 & 9.493 \\
$1 \mathrm{NiMo} / \mathrm{Ti}$ & 17.0 & 3.780 & 9.490 \\
$2 \mathrm{NiMo} / \mathrm{Ti}$ & 16.95 & 3.785 & 9.491 \\
$3 \mathrm{NiMo} / \mathrm{Ti}$ & 16.9 & 3.785 & 9.491 \\
4NiMo/Ti & 17.1 & 3.783 & 9.492 \\
\hline
\end{tabular}

a Average Standard Error: Size; $1.3 \mathrm{~nm}$; cell parameters; $0.005 \AA$.

Table 2

Morphological properties and band gag energy for the samples. ${ }^{\text {a }}$

\begin{tabular}{lllll}
\hline Sample & $\begin{array}{l}\text { BET Surface area } \\
\left(\mathrm{m}^{2} \mathrm{~g}^{-1}\right)\end{array}$ & $\begin{array}{l}\text { Pore volume } \\
\left(\mathrm{cm}^{3} \mathrm{~g}^{-1}\right)\end{array}$ & Pore size $(\mathrm{nm})$ & $\begin{array}{l}\text { Band Gap } \\
(\mathrm{eV})\end{array}$ \\
\hline $\mathrm{Ti}$ & 31.6 & 0.059 & 7.5 & 3.2 \\
$1 \mathrm{NiMo} / \mathrm{Ti}$ & 31.7 & 0.059 & 7.5 & 3.2 \\
$2 \mathrm{NiMo} / \mathrm{Ti}$ & 31.0 & 0.057 & 7.4 & 3.2 \\
$3 \mathrm{NiMo} / \mathrm{Ti}$ & 30.2 & 0.056 & 7.4 & 3.2 \\
$4 \mathrm{NiMo} / \mathrm{Ti}$ & 29.4 & 0.053 & 7.3 & 3.2 \\
$\mathrm{NiMo}$ & 1.4 & 0.012 & 2.6 & 2.9 \\
\hline
\end{tabular}

a Average Standard Error: BET; $2.5 \mathrm{~m}^{2} \mathrm{~g}^{-1}$; Band gap; $0.03 \mathrm{eV}$.

light source and considering illumination by two couples of lamps (corresponding to suffixes A and B), the local net radiation flux $q_{n}$ of the lamp, as well as the fraction(s) of light transmitted $\left(\mathrm{F}_{\mathrm{T}}\right)$ or reflected $\left(\mathrm{F}_{\mathrm{R}}\right)$ at each component (sample, $\mathrm{s}$, or glass, $\mathrm{g}$ ) of the reactor system. Details of the model procedure followed to obtain $q_{\text {sup }}$ are fully described in the Supporting Information file and Ref. [14].

\section{Results and Discussion}

\subsection{Characterization results of initial samples}

The Ti reference included in Fig. 1 shows a diffraction pattern dominated by the anatase phase (PDF 21-1272; space group I4 1 /amd). As it was reported previously, calcination below or around $600{ }^{\circ} \mathrm{C}$ typically renders a highly crystalline pure anatase phase for the majority of the preparation methods used (sol-gel, chemical vapor deposition, etc.) and, particularly considering this contribution, using the microemulsion method [22]. The NiMo reference sample is also a single phase material with a pattern corresponding to a triclinic polymorph (space group P 1 ) [23]. The composite materials are dominated by the major anatase phase without apparent differences among them. The 


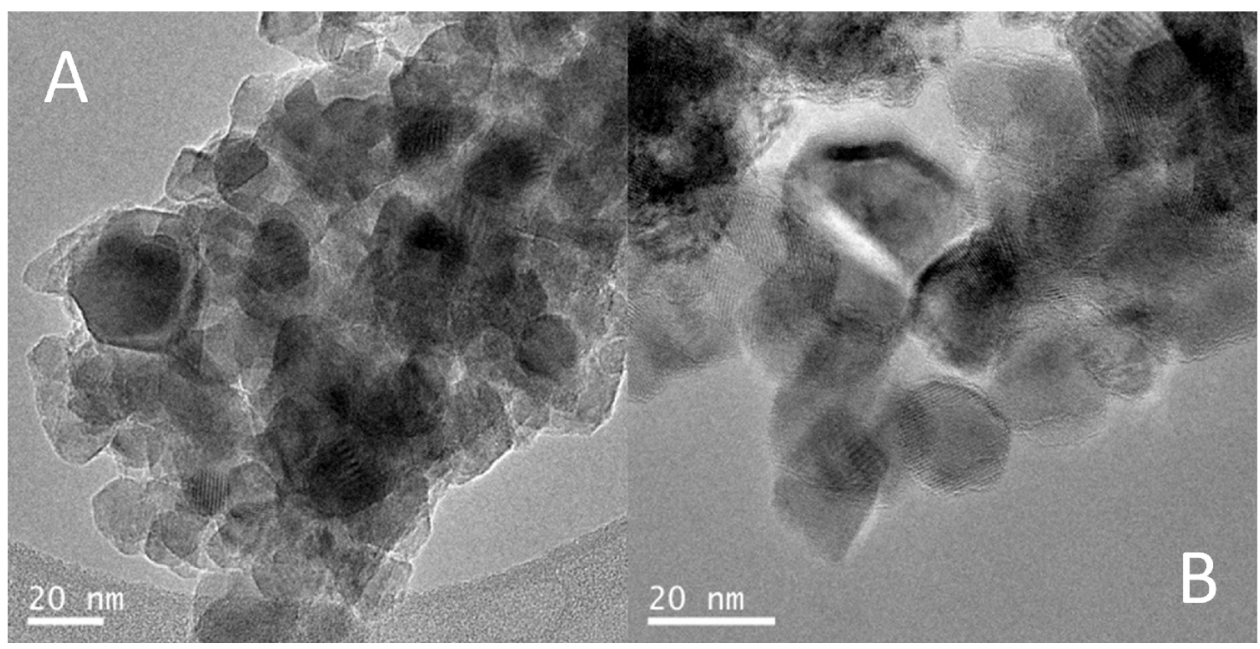

Fig. 2. TEM images of the $\mathrm{Ti}(\mathrm{A})$ and $4 \mathrm{NiMo} / \mathrm{Ti}(\mathrm{B})$ samples.

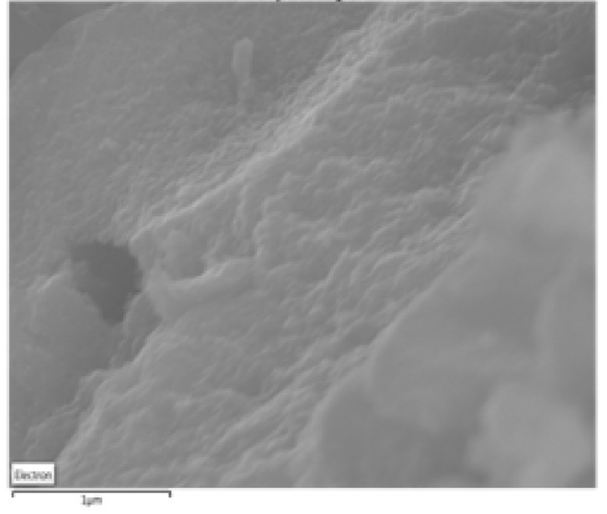

Mo La1

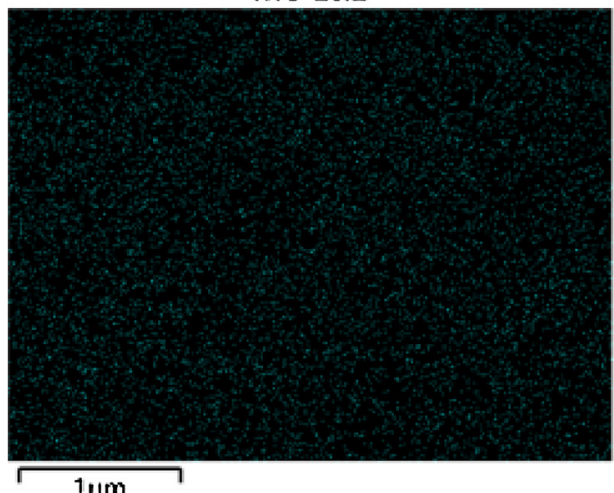

$1 \mu \mathrm{m}$

\section{Ti $K \alpha 1$}
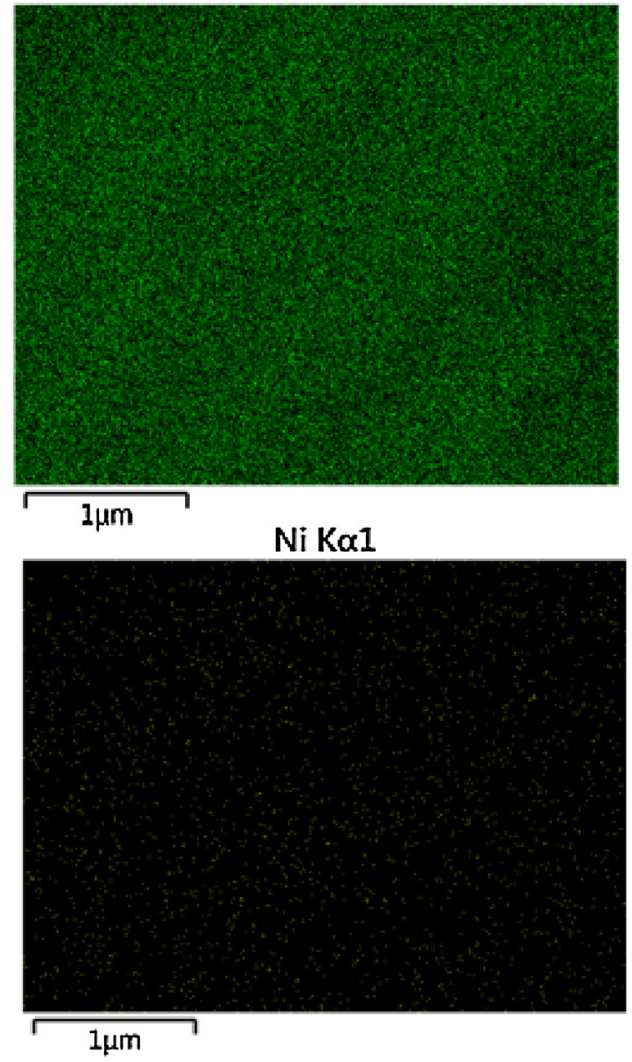

Fig. 3. SEM-XEDS analysis of the $3 \mathrm{NiMo} / \mathrm{Ti}$ sample.

deposition of the $\mathrm{NiMo}_{6}$ component is not producing significant changes in the oxide support. This is analyzed in detail in Tables 1 and 2. Table 1 summarizes the cell parameters and primary crystallize size of the anatase phase. A primary crystallite size of ca. $17 \mathrm{~nm}$ is obtained for all composite samples. Within experimental error we can point out the absence of changes with respect to the anatase reference for all observables (primary size and cell parameters) presented in Table 1 for the composite samples. In Table 2 the morphological properties of the samples are collected. Considering reference systems, we obtained an anatase powder with relatively high surface area (around $31 \mathrm{~m}^{2} \mathrm{~g}^{-1}$ ) while the NiMo reference sample displays a limited value (ca. $1.5 \mathrm{~m}^{2} \mathrm{~g}^{-1}$ ). The composite samples show rather similar values to the anatase reference, not only in terms of surface area but also in terms of pore size and volume. We note that according to Table 2 our anatasecontaining materials are mesoporous solids with porosity dominantly originated from the void volume created by the agglomeration of primary particles.

The structural and morphological similarity between the composite samples and the bare titania reference sample were also confirmed by microscopy analysis. Fig. 2 shows a comparison of TEM micrographs for the $\mathrm{Ti}$ and $4 \mathrm{NiMo} / \mathrm{Ti}$ samples. Using TEM the presence of the $\mathrm{NiMo}_{6}$ component is not detected (XEDS can do it; see below) while the anatase crystallites are rather similar in both micrographs. The anatase crystallites have sizes between 12 and $25 \mathrm{~nm}$ in both catalysts. In 

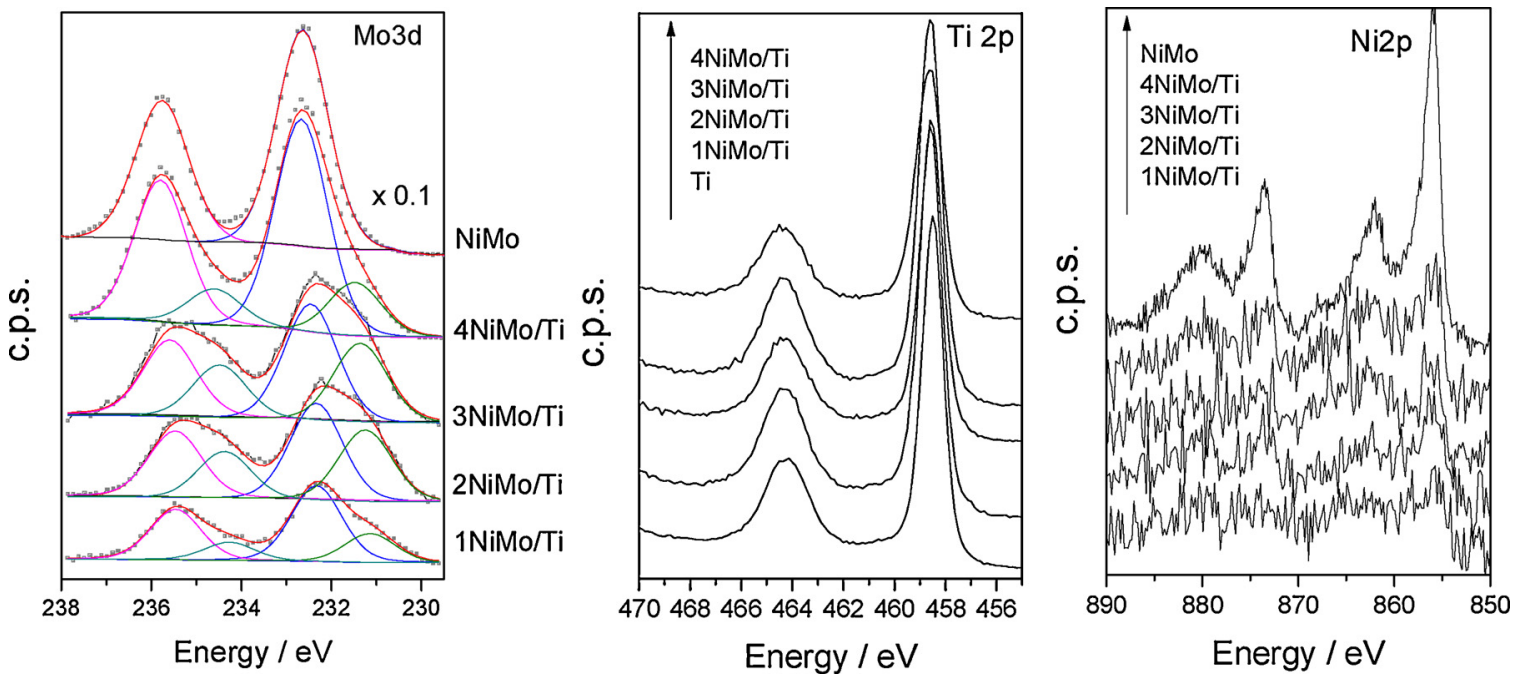

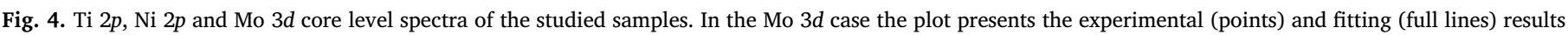
considering two Mo oxidation states.

Table 3

XPS observables (binding energy and atomic percentage or ratio) for the samples. ${ }^{\text {a }}$

\begin{tabular}{|c|c|c|c|c|c|c|c|}
\hline \multirow{2}{*}{$\begin{array}{l}\text { Sample } \\
\mathrm{Ti}\end{array}$} & \multicolumn{2}{|l|}{ Mo $3 d_{5 / 2}$} & \multirow{2}{*}{$\begin{array}{l}\mathrm{Ni} 2 p_{3 / 2} \\
\mathrm{Ni}^{2+} \\
\text { B.E. }(\mathrm{eV})\end{array}$} & \multirow{2}{*}{$\begin{array}{l}\text { Ti } 2 p_{3 / 2} \\
\mathrm{Ti}^{4+} \\
\text { B.E. }(\mathrm{eV})\end{array}$} & \multicolumn{3}{|l|}{ Atomic ratio } \\
\hline & $\mathrm{Mo}^{5+}$ B.E.(eV)/at. $\%$ & $\begin{array}{l}\mathrm{Mo}^{6+} \\
\text { B.E: }(\mathrm{eV}) / \mathrm{at} \%\end{array}$ & & & $\mathrm{Mo}^{5+} / \mathrm{Mo}^{6+}$ & $\mathrm{Mo} / \mathrm{Ti}$ & $\mathrm{Ni} / \mathrm{Mo}$ \\
\hline 1NiMo/Ti & 231.1/16.1 & $232.3 / 43.8$ & 856.2 & 458.6 & 0.37 & 0.03 & 0.14 \\
\hline 2NiMo/Ti & $231.2 / 24.8$ & $232.3 / 35.1$ & 856.3 & 458.6 & 0.71 & 0.06 & 0.13 \\
\hline 3NiMo/Ti & $231.3_{5} / 26.7$ & $232.5 / 36.2$ & 856.4 & 458.7 & 0.65 & 0.07 & 0.15 \\
\hline 4NiMo/Ti & $231.5 / 11.7$ & $232.7 / 48.1$ & 856.2 & 458.6 & 0.24 & 0.12 & 0.13 \\
\hline NiMo & n.f. & $232.6 / 60.1$ & 856.2 & - & - & - & 0.15 \\
\hline $\mathrm{Ti}$ & - & - & - & 458.5 & - & - & - \\
\hline
\end{tabular}

${ }^{a}$ Average Standard Error: Binding Energies; $0.1 \mathrm{eV}$; Atomic ratio 9.9\%.

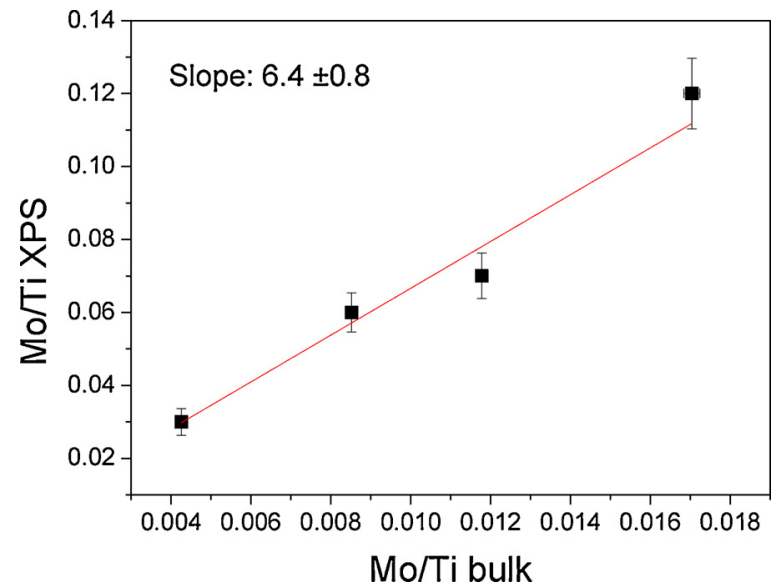

Fig. 5. Parity plot between the Mo/Ti atomic ratio obtained by chemical analysis and XPS.

summary, the XRD and TEM analyses indicate, as can be expected, that the major and highly crystalline anatase phase dominates the structural, morphological and surface properties of the composite samples. We note that the deposition of the $\mathrm{NiMo}_{6}$ component at the anatase surface would favor its stabilization, as it has been previously mentioned in the literature for other POMs [24-26]. Information about the NiMo component of composite samples is obtained with the help of SEM-XEDS. Fig. 3 shows data for the $3 \mathrm{NiMo} / \mathrm{Ti}$ sample while results concerning the $\mathrm{Ti}$ reference and other xNiMo/Ti samples are presented in Figs. S6-S8 at the supporting information section. The XEDS plots of the Mo signal (and to a lower extent Ni due to its limited weight in composite samples) provide evidence of the good homogeneity achieved in the deposition of $\mathrm{NiMo}_{6}$ species over the anatase surface. No significant differences are encountered among the xNiMo/Ti composite samples. This will be corroborated using XPS.

The samples were thus subjected to an XPS study. Fig. 4 provides plots of high resolution scans concerning $\mathrm{Ti} 2 p$, Ni $2 p$, and Mo $3 d$ regions. A summary of peak positions for the different chemical states of the 3 elements mentioned as well as the surface atomic ratios (between pertinent elements) is presented in Table 3 . Ti $2 p$ core level spectra do not display significant variation among samples. The corresponding $\mathrm{Ti}$ $2 p_{3 / 2}$ peak is located at $458.6 \mathrm{eV}$ and is assigned to a Ti(IV) oxidation state [27]. The Ni $2 p$ spectra are noisy, but the observed Ni $2 p_{3 / 2}$ binding energy values are similar to that of NiMo reference (see Table 3). The Ni $2 p_{3 / 2}$ signal obtained for the NiMo reference is located at $856.2 \mathrm{eV}$, and can be assigned to $\mathrm{Ni}(\mathrm{II})$ species [27]. The chemical analysis of $\mathrm{Ni}$ in the $3 \mathrm{NiMo} / \mathrm{Ti}$ sample renders a $0.34 \mathrm{wt}$. \% content, in reasonable agreement with the $0.32 \mathrm{wt}$. \% expected. The low Ni content justifies the level of noise detected in the Ni $2 p$ spectra of the composite samples presented in Fig. 4. The larger quantity of Mo (6 times) with respect to Ni facilitates its detection. Mo $3 d$ core level signals show differences among composite samples and also with respect to the NiMo reference. These differences are better analyzed with the help of the numerical data collected in Table 3 . The Mo $3 d_{5 / 2}$ core level signal of composite samples contains contributions at 231.1-231.5 and 232.3-232.6 eV, assigned to $\mathrm{Mo}(\mathrm{V})$ and $\mathrm{Mo}(\mathrm{VI})$ species, respectively [26]. The reduced species is not detected in the NiMo reference and its appearance is typically ascribed to interaction with the support [28]. The binding energy of the two Mo species shifts to lower energy from 

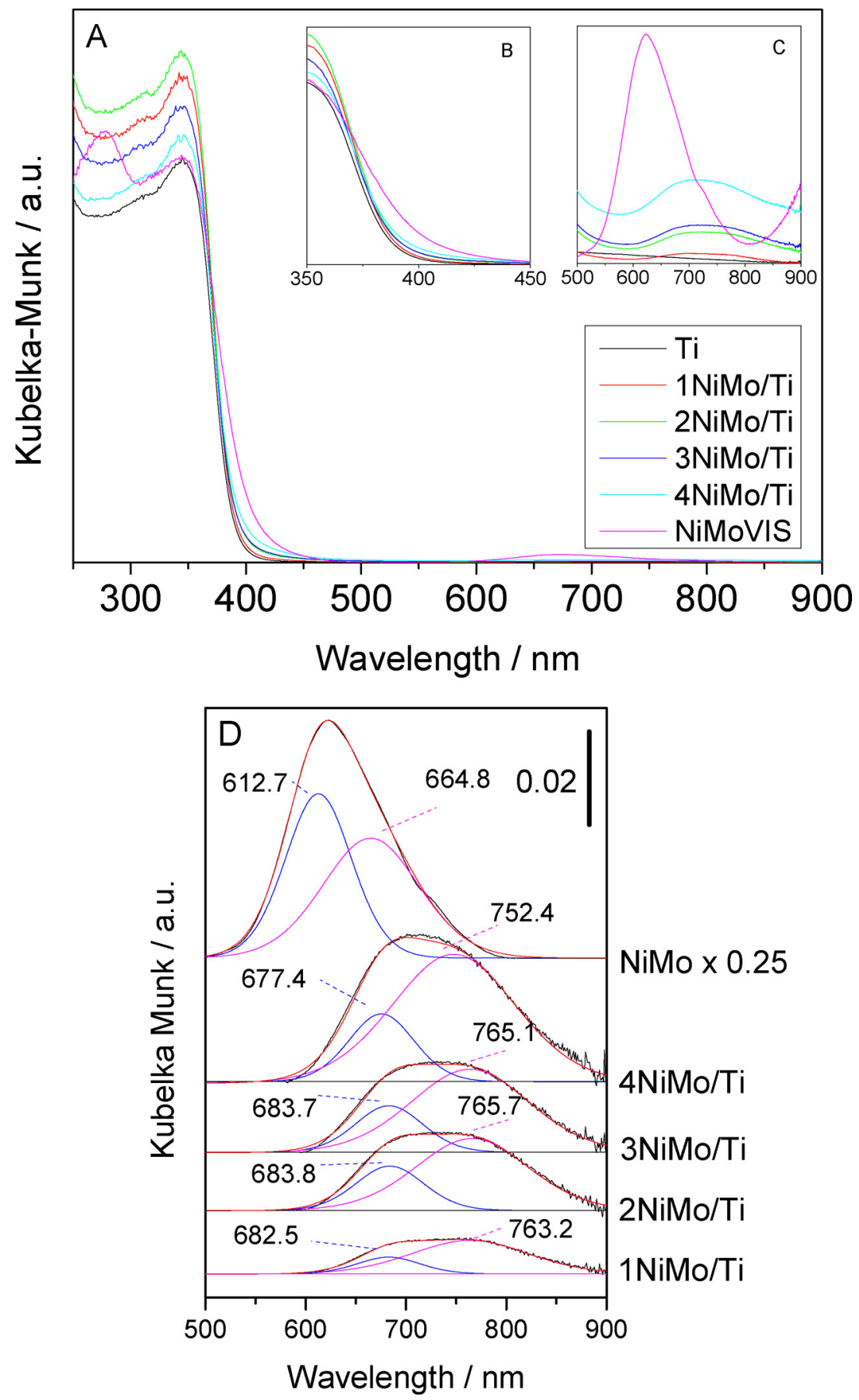

Fig. 6. UV-visible diffuse reflectance spectra of the samples. Panels A-C: general and detailed views of the spectra. Panel D: fitting of the Ni d-d transitions.

the reference(s) indicating also a change of the supported species from the bulk-type reference(s). This shift is a function of the NiMo loading. Moreover, the ratio between the two Mo species varies along the series, with a maximum for intermediate $\mathrm{NiMo}_{6}$ loadings.

The $\mathrm{Ni} / \mathrm{Mo}$ atomic ratios (Table 3) obtained for the composite samples are equal (within experimental error) to the one obtained for the NiMo reference, indicating that the heteropolyacid main structure would be preserved after deposition onto the titania surface. Interestingly, the dispersion of the $\mathrm{NiMo}_{6}$ species as measured with the Mo/Ti ratio seems to be relatively constant. Fig. 5 provides evidence for this statement by plotting the $\mathrm{Mo} / \mathrm{Ti}$ atomic ratio obtained from chemical analysis (bulk) and from XPS. A rough linear trend is obtained, suggesting that the anatase surface covered by the $\mathrm{NiMo}_{6}$ species drives roughly to similar dispersion values of the $\mathrm{NiMo}_{6}$ component. As mentioned, this conclusion agrees with the SEM-XEDS analysis of the samples. The linear behaviour displayed in Fig. 5 indicates that roughly $1 / 6$ of the atoms could be exposed to the gas atmosphere. Of course, this may be a simplification as a fraction of the $\mathrm{NiMo}_{6}$ component may be occluded at a pore structure of anatase, being thus not fully accessible to surface sensitive techniques. Although this may occur to some extent, the similar pore size and volume and, in general terms, morphology, of the composite samples and the $\mathrm{TiO}_{2}$ reference would indicate that this may not be a critical point to compare dispersion among our series of composite samples.

To complete the characterization of the samples, Fig. 6 presents the UV-visible spectra of the samples. The spectra of the composite samples resemble closely the one of the anatase reference. Such reference displays the characteristic shape of a semiconductor, with a sigmoidal 

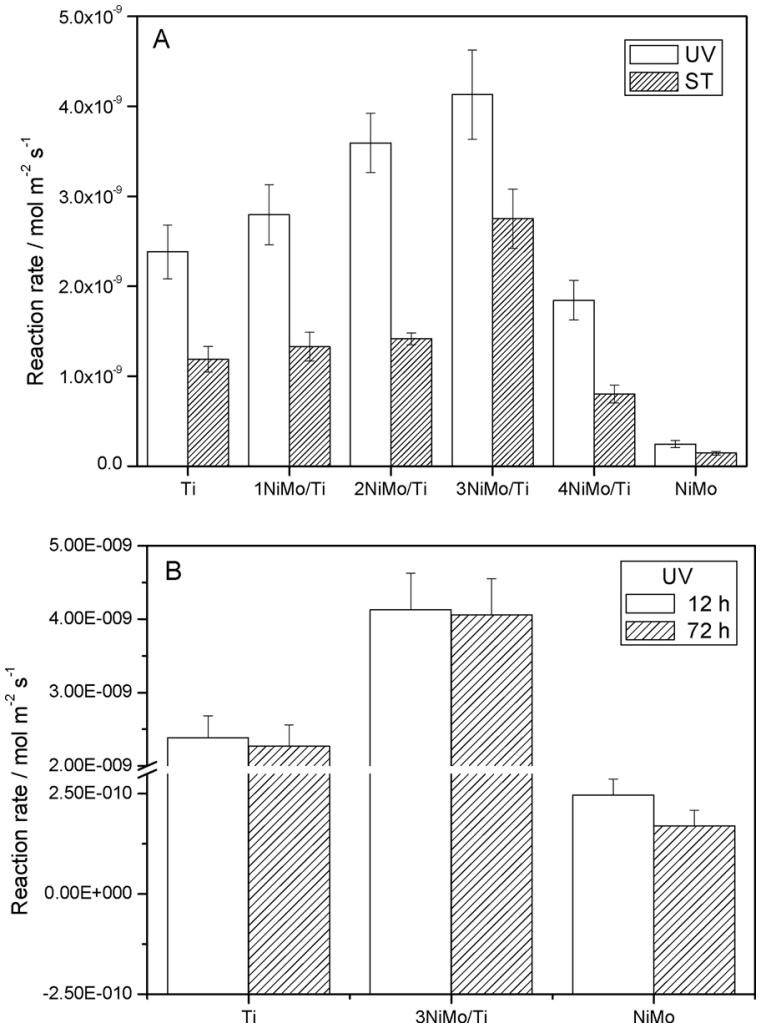

Fig. 7. Toluene photo-oxidation reaction rates obtained under UV and Sunlighttype (ST) illumination conditions (A) 12 hours; and (B) comparison between 12 and 72 hours of time on stream.

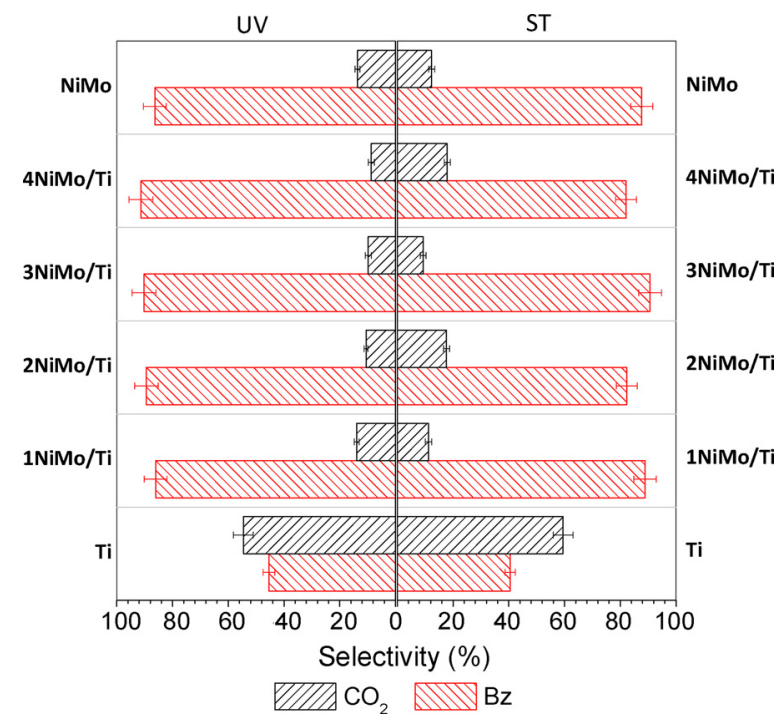

Fig. 8. Selectivity of the toluene photo-oxidation for the samples under UV and Sunlight-type (ST) illumination conditions. Bz; Benzaldehyde; $\mathrm{CO}_{2}$ : carbon dioxide.

shape in the $350-400 \mathrm{~nm}$ range. This is a direct consequence of the density of states, which decreases significantly in the gap region. Considering that anatase is an indirect band gap semiconductor as it is customary assumed in the literature [29], we obtained a band gap value of $3.2 \mathrm{eV}$ (Table 1). This value is also characteristic of the composite samples which therefore do not present changes on the band gap energy within experimental error. The NiMo reference sample presents a lower bang gap energy (Table 2). Interestingly the UV-visible spectra of the samples containing the $\mathrm{NiMo}_{6}$ component displays also features in the
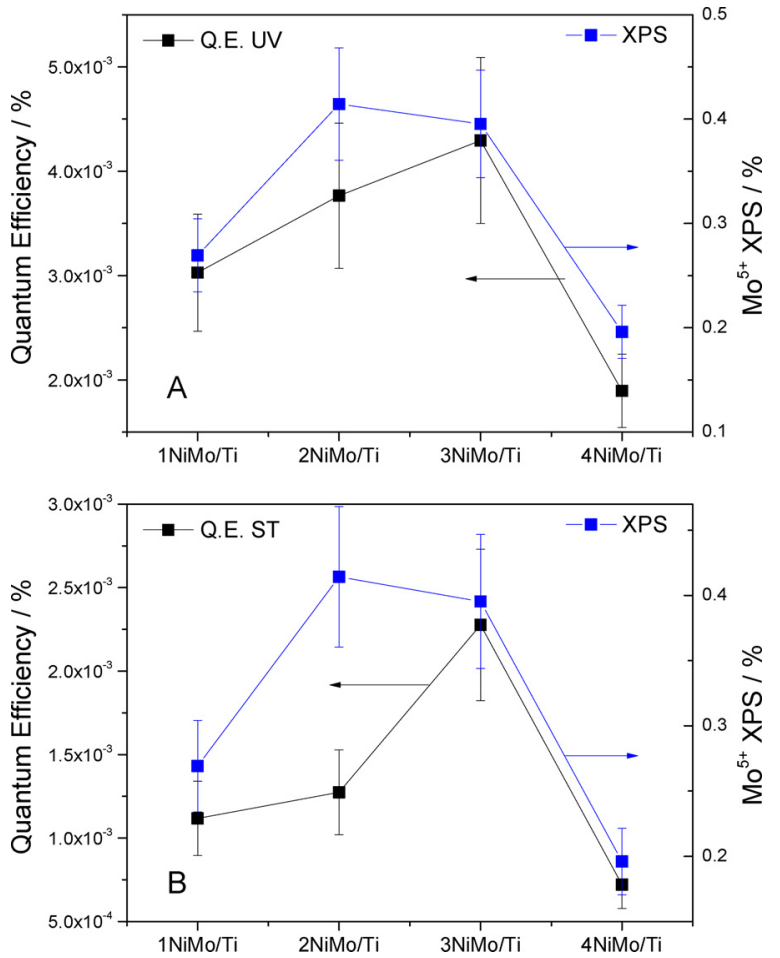

Fig. 9. Quantum efficiency and $\mathrm{Mo}^{5+}$ XPS percentage (over total Mo) for the composite samples. (A) UV; (B) Sunlight-type illumination.

500-900 nm region (see panel D of Fig. 6). These features would correspond to $\mathrm{Ni}(\mathrm{II}) \mathrm{d}$-d transitions, likely connected with the (octahedral symmetry) ${ }^{3} \mathrm{~A}_{2 \mathrm{~g}}(\mathrm{~F}) \rightarrow{ }^{3} \mathrm{~T}_{1 \mathrm{~g}}(\mathrm{~F})$ transition although at high wavenumbers we can have additional contributions from spin forbidden transitions $[30,31]$. Differences in d-subband splitting between the pure NiMo reference and composite samples could be related to a lowering of the crystal field symmetry from the octahedral type characteristics of the pure $\mathrm{NiMo}_{6}$ compound $[30,31]$. The more important point is that all $\mathrm{Ni}$ (II) d-d transitions suffer a consistent shift to higher wavenumbers. According to the Ni(II) Tanabe Sugano plots [32] and the electronic transition assignment carried out, such a consistent energy behaviour allows to infer a decrease of the crystal field experienced by the cation. This may have several causes related to the interface effect in the $\mathrm{NiMo}_{6}$ structure. The modification (both in energy position and intensity) of the $\mathrm{Ni}(\mathrm{II})$-related band positions depends on the $\mathrm{NiMo}_{6}$ content of the composite sample (Fig. 6). The energy shift seems similar for the samples having low $\mathrm{NiMo}_{6}$ content and decreases modestly for the 4NiMo/Ti sample.

In summary, in the composite samples the $\mathrm{NiMo}_{6}$ component is altered if compared with the NiMo parent reference system. This affects both cations, Ni and particularly Mo. Although Ni maintains its 2+ oxidation state, it electronic properties (more precisely d-subband splitting and mean energy position) are modified by interaction with the support. Mo has a more drastic change with presence of $5+$ chemical states in addition to the $6+$. Only the $6+$ oxidation state is characteristic of the parent material. The Ni/Mo atomic ratio does not change however through the series of composite samples. The modification of the electronic and structural properties of the $\mathrm{NiMo}_{6}$ component by interaction with anatase would thus be of significance to control its influence in the composite photocatalytic properties. This modification is clearly dependent on the $\mathrm{NiMo}_{6}$ component loading of the composite samples. On the contrary, anatase suffers rather modest (if any) modification(s) by presence of the alien surface species. 


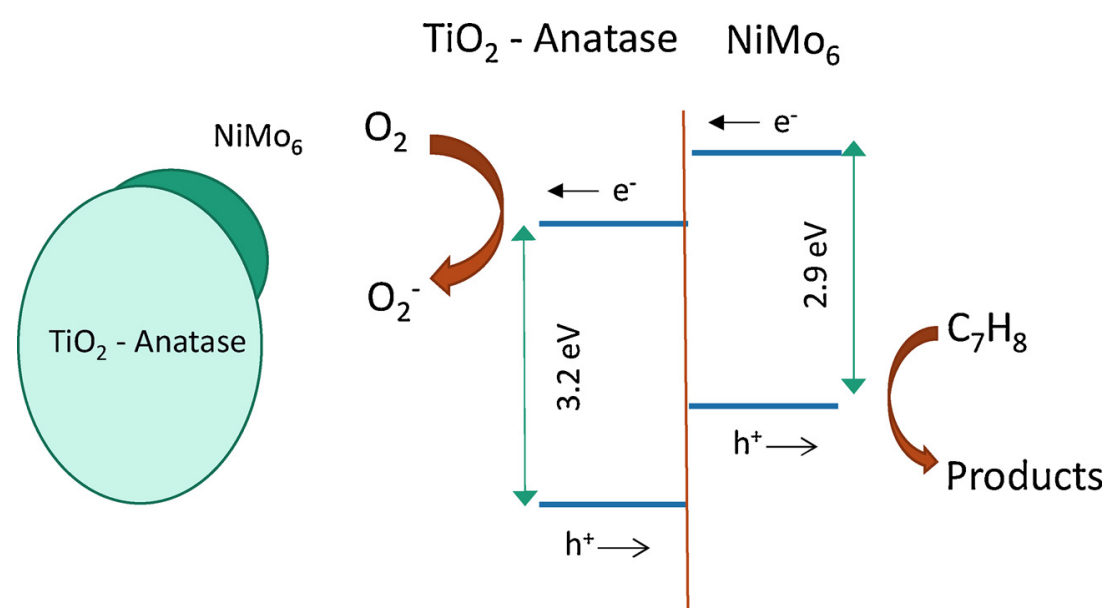

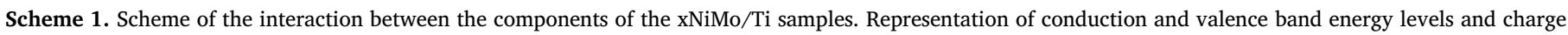
flow upon illumination are also included.

\subsection{Catalytic results}

The reaction rates measured for the toluene photo-oxidation reaction are graphically displayed in Fig. 7. The pure anatase (titania) sample shows a reaction rate comparable with previous ones corresponding to well-crystallized anatase-dominated samples. In fact, our bare anatase powder is more active (ca. 1.5 times or $150 \%$ ) than the commercial P25 reference, previously tested with the same setup used in this work [33]. The NiMo reference is active in the reaction but displays a rather modest activity, more than 10 times lower than anatase. The composite samples display increasing activity from the anatase reference up to a $3 \mathrm{wt}$. \% of the $\mathrm{NiMo}_{6}$ component, decreasing after it markedly. Activity reaches maximum values under both UV and sunlight-type illumination for the $3 \mathrm{NiMo} / \mathrm{Ti}$ sample. Enhancement factors of ca. 1.7 and 2.3 can be measured with respect to the Ti reference under, respectively, UV and sunlight-type illumination conditions. Such enhancement factors clearly show the potential of the materials for toluene photo-oxidation. The reaction rate maximum, ca. $3 \times 10^{-2}$ micromol $\mathrm{g}^{-1} \mathrm{~h}^{-1}$, is still orders of magnitude below the (thermal catalysis) industrial processes for toluene photo-oxidation, but reaction takes place at room temperature and pressure while the industrial processes require temperatures always above $140{ }^{\circ} \mathrm{C}$ and pressures from 2 to 8 atmospheres [34,35].

The stability of the $3 \mathrm{NiMo} / \mathrm{Ti}$ sample and $\mathrm{Ti}$ and NiMo reference samples was measured under UV and Sunlight-type illumination conditions in tests completing $72 \mathrm{~h}$ of time on stream. No change (within experimental error; see panel B of Fig. 7) was detected for titania containing samples. In the case of the Ti reference we previously presented this result $[36,37]$. The deposition of the $\mathrm{NiMo}_{6}$ component does not affect the stability in the composite sample while a relatively mild decay is observed in the NiMo reference catalyst. For the $3 \mathrm{NiMo} / \mathrm{Ti}$ sample we also tested the activity in absence of water (see Fig. S9). These tests show the need of water presence in the reaction mixture to obtain stable activity.

To complete the analysis of the photocatalytic properties of the samples, the selectivity of toluene photo-oxidation is presented in Fig. 8 . The selectivity is constant over the time on stream interval tested in Fig. 7. In the majority of the publications reported in the literature, the gas-phase photo-oxidation of toluene renders benzaldehyde as a partial oxidation product and carbon dioxide as the total oxidation one $[19,33,36,38-40]$. Usually other products such as benzene, formaldehyde and others minor components are toluene-concentration dependent and their concentrations are maximized in conditions of limited water content in the reaction mixture. Limited water at the reaction mixture may increase reaction rate and the concentration of the mentioned minor products but decreases significantly the stability of the catalysts $[12,41,42]$. Absence of water in the reaction mixture is however detrimental for activity as shown in Figure S9. This is easy to rationalize as toluene photo-oxidation is known to proceed through a hydroxyl-radical mechanism in titania based materials [12,40,43]. Hydroxyl radicals are obtained from the attack of holes to water molecules and/or hydroxyl entities of the solid surface. The radical species reacts with the methyl moiety of toluene to render an organic radical which subsequent interaction with oxygen renders benzaldehyde. Further attack of radical species generates benzoic acid. Other organic products are generated by hydroxyl radical attack to the aromatic ring and initial formation of cresol-type intermediates, a step which would be followed by the subsequent ring opening within an essentially unknown mechanism [12,40,43].

Our titania reference displays exclusively carbon dioxide and benzaldehyde as reaction products. The $\mathrm{NiMo}_{6}$ pure phase renders benzaldehyde as the dominant product. In the case of the composite samples we observe a similar result, with benzaldehyde selectivity around $90 \%$, irrespective of the (composite) sample and the illumination conditions. This contrasts with the behavior of the Ti reference (Fig. 8). We can mention that photo-catalytic production of benzaldehyde has been attempted under UV excitation from benzyl alcohol as well as model lignin compound [44-46], but is it also very interesting to obtain it from a raw chemical such as toluene. As mentioned, toluene partial oxidation is industrially carried out using thermal Co-based catalysts [13,34,35].

In summary, the $3 \mathrm{NiMo} / \mathrm{Ti}$ material is a highly active and stable catalyst for toluene photo-oxidation in presence of water. This concerns a significantly improved performance with respect to the references as measured by the quantum efficiency. The efficiency enhancement ratios with respect to the Ti reference are 1.4 (Fig. 9A) and 2.0, respectively, under UV and sunlight-type (see Fig. 9B) operation. Interestingly, the enhancement factor is higher under sunlight-type than UV illumination, indicating the significant profit that the composite system makes of the visible light photons. Moreover, the $\mathrm{NiMo}_{6}-\mathrm{TiO}_{2}$ composite system not only provides high activity but renders a reasonably high selectivity for benzaldehyde, an interesting product $[13,34,35]$. This occurs under UV and sunlight-type illumination. The composite system appears thus an interesting candidate for partial oxidation processes under sunlight illumination, rendering a "green" process.

\subsection{Interpretation of catalytic properties}

As discussed, the NiMo/Ti composite system shows high and stable activity as well as a significant selectivity to added-value partial oxidation compounds derived from toluene. To interpret in first place activity behavior through the series of samples, Fig. 9 displays the 

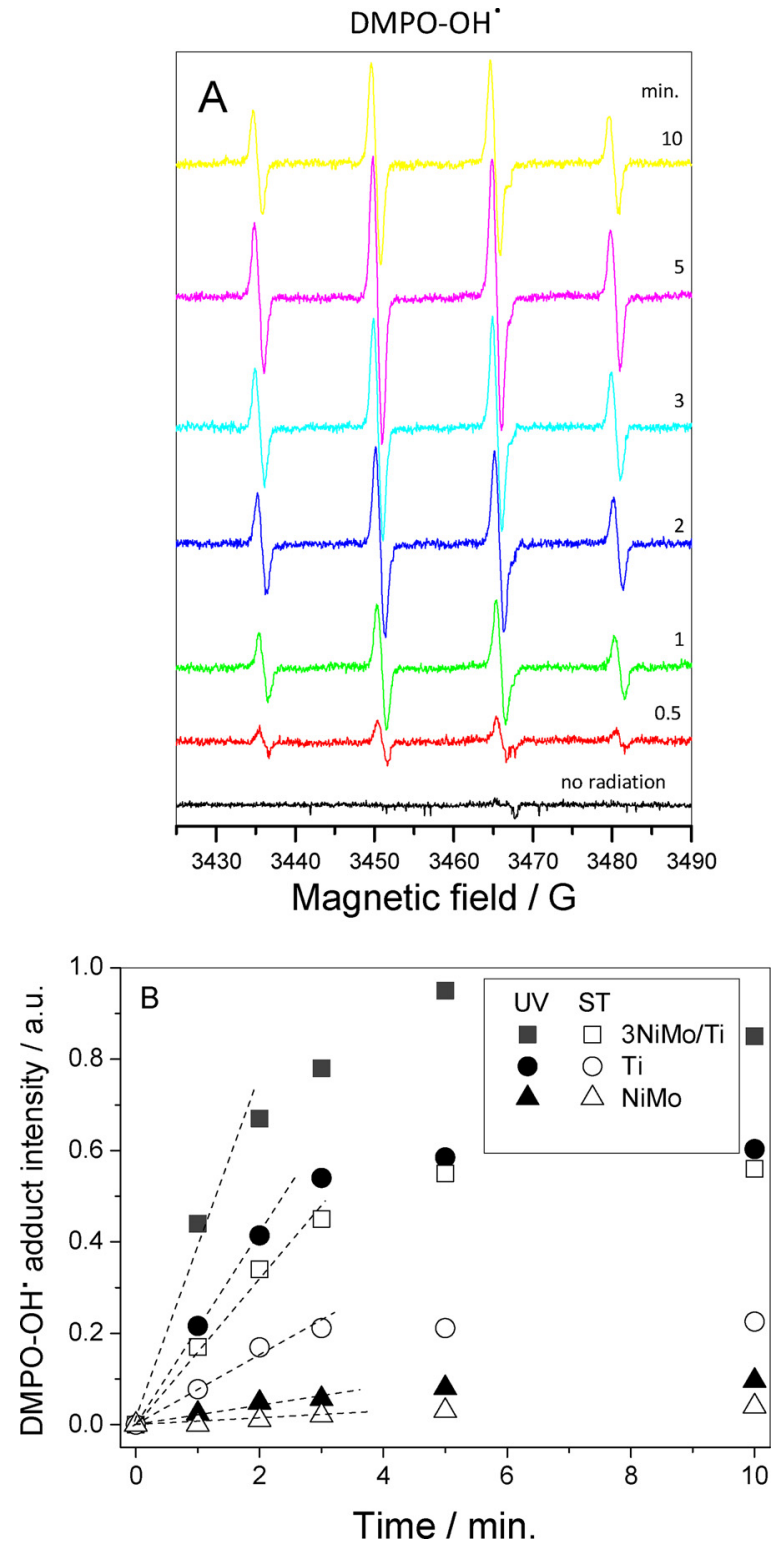

Fig. 10. (A) EPR spectra of the DMPO-OH adduct obtained under UV excitation for the $3 \mathrm{NiMo} / \mathrm{Ti}$ sample; (B) time evolution of the radical species signal intensity obtained under UV and sunlight-type (ST) illumination conditions. Slope (s) of the DMPO-OH adduct formation rate is (are) shown as dashed lines.

quantum efficiency values for both illumination conditions tested as well as the $\mathrm{Mo}^{5+}$ fraction (over total Mo) measured by XPS in the initial samples. The latter attempts to provide a measure of the interface influence in the $\mathrm{NiMo}_{6}$ component. As detailed in Section 3.1, the interface between components has structural and electronics effects in the solid properties. The most interesting point coming from Fig. 9 is the relatively similar behavior detected between the activity and XPS observables presented. The zone of maximum photo-activity and $\mathrm{Mo}^{5+}$ fraction is the same and concerns the $2 \mathrm{NiMo} / \mathrm{To}$ and $3 \mathrm{NiMo} / \mathrm{Ti}$ samples. Of course, the XPS observable is indicative of the specific cluster(s) properties driving maximizing activity but it is not necessarily in direct connection with the activity. In spite of it, both Mo and Ni cations suffer structural and electronic modification ascribed to the interaction with the support and concerning a change in local symmetry of both cations as well as the electron enrichment of part of Mo, likely associated to a modification of the neighboring oxygens shared with titanium cations of the support. We note that, due to the differences with the bulk material, the absence of a suitable reference for the $\mathrm{NiMo}_{6}$ component at the titania surface together with its nanometric particle size pose a considerable difficulty for the analysis of the electronic details of the interaction between components in the composite materials.

The activity and selectivity differences between the bare reference systems and the composite system would indicate that the photo-oxidation of toluene grounds may change throughout the sample series. To further progress in the interpretation of these catalytic observables we analyzed the interaction of the materials. A first relevant information comes from the study of the band structure of the composite materials. The conduction and valence bands ( $\mathrm{CB}$ and $\mathrm{VB}$ ) edges of anatase (band gap of $3.2 \mathrm{eV}$ according to Table 1 ) are at ca. -0.07 and $+3.1 \mathrm{eV}$ vs. the NHE [47]. The CB and VB edges of the $\mathrm{NiMo}_{6}$ component can be calculated according to $[48,49]$ :

$E_{\mathrm{VB}}=X-E_{C}+0.5 E_{G}$

Where $E_{\mathrm{VB}}$ is the energy of the $\mathrm{VB}, \mathrm{X}$ is the electronegativity of the semiconductor, $E_{C}$ is the energy of the free electron (approximately $4.5 \mathrm{eV}$ ) and $E_{G}$ is the band gap energy. The electronegativity of the semiconductor is measured as the geometrical mean value of the absolute electronegativity of the constituent atoms. The latter is in turn calculated as the average value of the electron affinity and ionization potential of the atom. Once obtained the $E_{\mathrm{VB}}$ value, obtaining the corresponding $E_{\mathrm{CB}}$ value is straightforward, taking into account the band gap energy. For the $\mathrm{NiMo}_{6}$ component supported at the anatase surface the method just described renders values of ca -0.6 and $+2.3 \mathrm{eV}$ vs. the NHE for, respectively, the conduction and valence band energy levels. Although these are only approximate values they provide information about the charge handling at the composite system. Using this methodology we draw schematically the band positions of the composite system components in Scheme 1. Such scheme dismisses band bending and other possible electronic interface effects (although the nanometric size of the components would lead to a small band edge energy drift due to limited band bending effects [1]). In any case, the electronic contact between the components of the composite system allows an efficient separation of charge after illumination. Holes would be accumulated in the $\mathrm{NiMo}_{6}$ component while electrons would be accumulated in the anatase component. An effective charge separation would thus take place.

To confirm the last point and considering that toluene photo-oxidation is a hole-driven mechanism [12,40,43], we studied the formation of hydroxyl radicals by the samples using EPR with the help of a probing molecule, DMPO, which selectively interacts with radical hydroxyl entities rendering an adduct product (DMPO-OH). UV and sunlight-type irradiation of DMPO-containing sample water suspensions give rise to a single signal in our samples (illustrative example shown in Fig. 10A). The corresponding parameters $\left(2.0056, \mathrm{a}_{\mathrm{N}}=14.9 \mathrm{G}\right.$, $\mathrm{a}_{\mathrm{H}}=14.9 \mathrm{G}$ ) are characteristic of DMPO-OH adducts generated by the reaction of the probe molecule and hole-related species [50-52]. The accumulation of DMPO-OH radical adducts grows continuously in all cases but such radicals have a limited stability and a maximum concentration as a function of time is always detected (panel B of Fig. 10). The latter is an effect of multiple additions, within consecutive reactions, of $\mathrm{OH} \cdot$ radicals to DMPO molecules to yield diamagnetic species [52-54]. So, the initial slope of the DMPO-OH adduct formation is considered a robust observable to compare the hydroxyl formation capability of the samples. Fig. 10 shows slopes in qualitative agreement with the catalytic results presented in Fig. 7. EPR shows that the three samples produce hydroxyl radicals and would thus present activity in our reaction (as shown in Fig. 7 the three samples transform toluene). The 3NiMo/Ti shows higher slopes than Ti and this last sample than the NiMo reference (note that the last sample has a rather low surface area and may suffer dissolution in water). More importantly, the $3 \mathrm{NiMo} / \mathrm{Ti}$ vs. Ti ratio of slopes takes the value of 1.8 and 2.7 for, respectively, UV and sunlight-type illumination. These values track the 1.4. and 2.0 values of the corresponding quantum efficiency ratio. Therefore, the experiment shows that the formation of the key radical species of the 


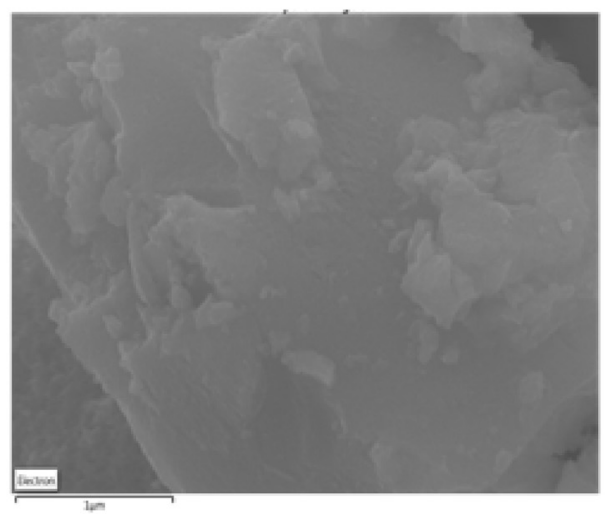

Mo L $\alpha 1$

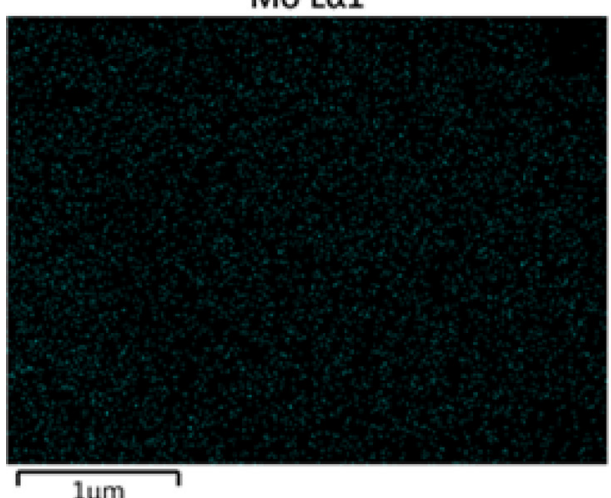

Fig. 11. SEM-XEDS analysis of the 3NiMo/Ti sample after reaction.

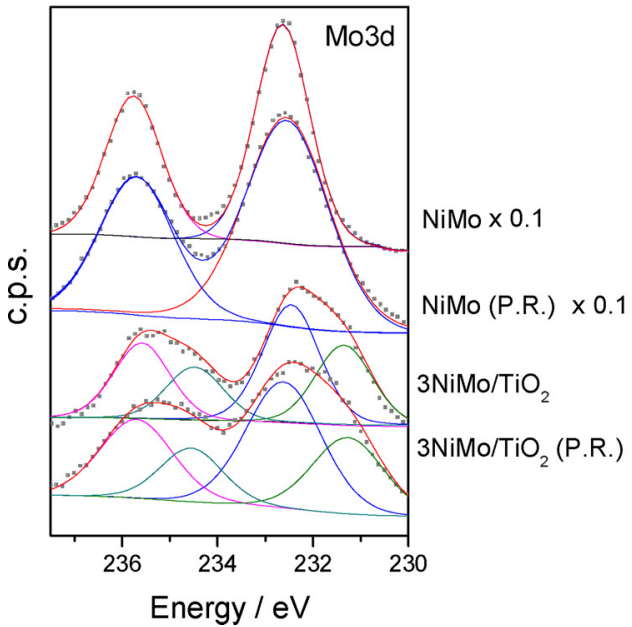

$\mathrm{Ti} K \alpha 1$

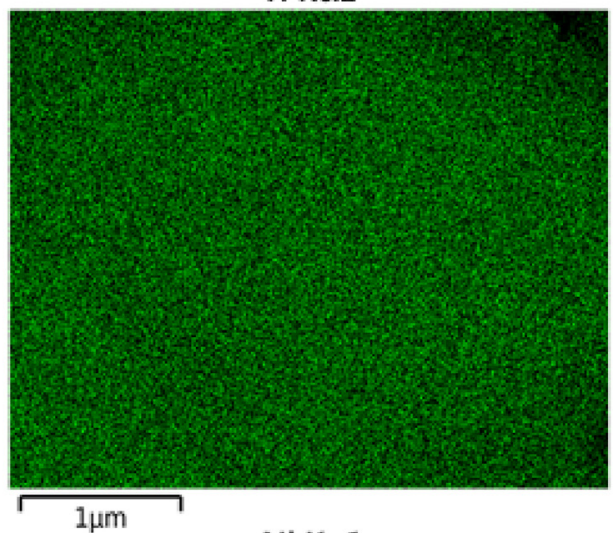

Ni K $\alpha 1$

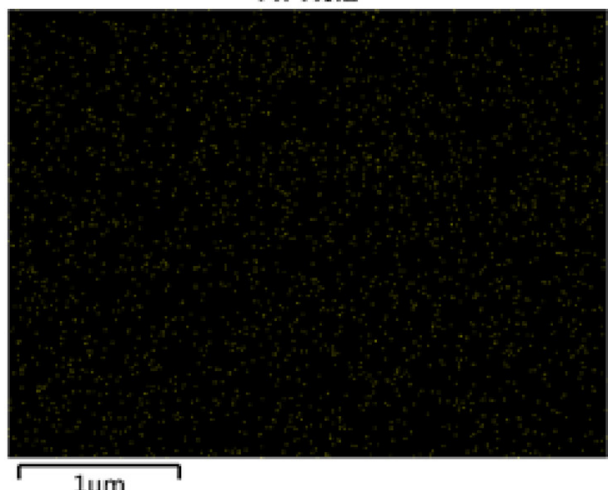

$1 \mu \mathrm{m}$

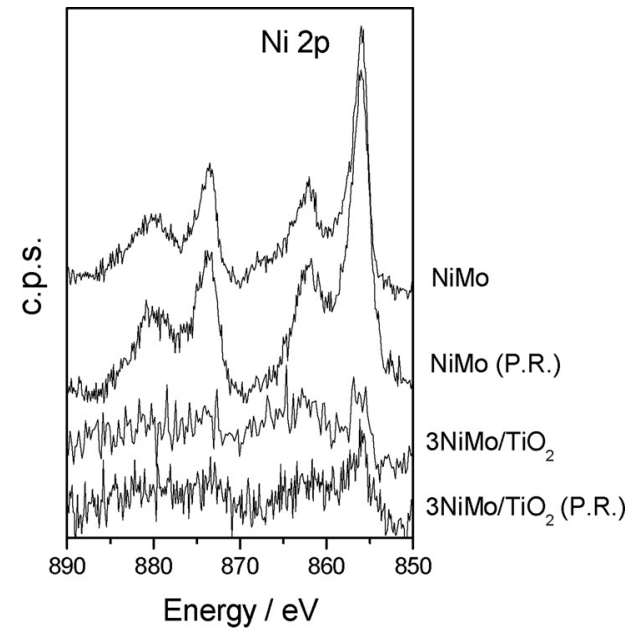

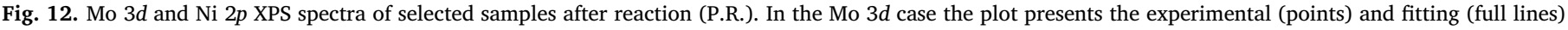
results considering two Mo oxidation states.

oxidation process is significantly enhanced in the composite system and this is directly reflected in the catalytic behavior of the samples.

To end the analysis of the catalytic behavior of the series of samples, we would consider the optimization of the photo-activity within this new $\mathrm{NiMo}_{6}-\mathrm{TiO}_{2}$ composite system. From the above discussion it seems that the loading of the POM optimizing activity appears as a compromise of several physico-chemical variables. First to consider is the contact between components. From the characterization study we demonstrated that the dispersion of the $\mathrm{NiMo}_{6}$ component is roughly constant in the loading interval scanned. However, the interaction between components modifies both the Mo and (to a lesser extent) $\mathrm{Ni}$ cations, indicating continuous changes in the morphology of the interaction (more precisely of the minor component morphology) along the series of samples. So, a simple interpretation of the activity maximum is that the structural and electronic modification of the minor $\mathrm{NiMo}_{6}$ component triggers the optimization of the photo-activity (which considering Scheme 1 would favor charge separation) but such a positive modification is progressively diminishing as the size of the $\mathrm{NiMo}_{6}$ component entities increases about a certain point. This is clearly illustrated by Fig. 9 and the maximization of the fraction of $\mathrm{Mo}^{5+}$ seems a pointer where this structural/electronic modification (or in the macroscopic world, the $\mathrm{NiMo}_{6}$ content of the material) would favor catalytic properties. As mentioned, toluene photo-oxidation is a hole driven mechanism [12,40], and this charge carrier species would 
accumulate in the $\mathrm{NiMo}_{6}$ phase. The optimum may simply be a consequence of the maximization of the interaction (and optimum charge separation) between the two phases or components of the composite system. As shown by EPR, the interaction leads to an enhancement of hydroxyl species. The hole radical species supply to the NiMo component apparently promotes its catalytic properties (in a direct or indirect way, this point requiring further investigation). It can occur that the reaction (or the kinetically relevant step) would take place at the interface between the components of the composite system, being thus the modification of the $\mathrm{NiMo}_{6}$ component affecting indirectly to the activity. In this case, the "charge separation" drawing presented in Scheme 1, which does not account for specific interface effects, would be a simplified yet illustrative representation of the main events of the mechanism. On the other hand, the drastic change in selectivity occurring from the anatase reference (Fig. 8), even for small loading of the $\mathrm{NiMo}_{6}$ component, can be also justified according to Scheme 1, with the hole-related charge species "chemical".properties associated with the POM component (and not titania) in the $\mathrm{NiMo}_{6}-\mathrm{TiO}_{2}$ materials. Such property would drive to an increase of the yield of the partial oxidation product with respect to carbon dioxide and the titania reference. Note that this also suggests that a possible shadowing effect of the anatase surface would play a minor role in photo-activity.

Finally, to complete the study we analyze the stability issue with a physico-chemical analysis of selected samples after the long term reaction tests presented in Fig. 7B. The main morphological and structural properties of the post-reaction $3 \mathrm{NiMo} / \mathrm{Ti}$ sample are compared with the two parent (reference) systems in Table S1 of the supporting information section. No significant variation was observed for all observables included in such Table. Moreover, to analyze in detail the $\mathrm{NiMo}_{6}$ component, a SEM-XEDS analysis of the best catalyst, 3NiMo/Ti, was carried out (Fig. 11). The dispersion of the component over the anatase surface does not suffer alternation from the initial state (Fig. 3). An XPS analysis of the $\mathrm{NiMo}_{6}$ component after reaction was also carried out. Relevant results are displayed in Fig. 12. Focusing the analysis in the Mo 3d signal (as the Ni signal is rather weak for the composite sample) we can see that the surface component of the $3 \mathrm{NiMo} / \mathrm{Ti}$ sample is essentially unaltered. A relatively minor change is observed for the NiMo reference which may be related to the mild decrease of activity. The NiMo reference XPS signal broadens (and is shifted by a small amount, ca. $0.2 \mathrm{eV}$ ) indicating that the surface is likely more heterogeneous. In any case, the study of the $3 \mathrm{NiMo} / \mathrm{Ti}$ sample shows its structural, electronic and morphological stability under reaction conditions, justifying the stable activity presented in Fig. 7B.

\section{Conclusions}

In this work we synthesized $\mathrm{NiMo}_{6}-\mathrm{TiO}_{2}$ composite materials with different chemical composition defined by the loading of the minor $\mathrm{NiMo}_{6}$ component. The physico-chemical characterization indicates that such minor $\mathrm{NiMo}_{6}$ component is modified by interaction with anatase, altering its electronic and structural properties as a function of the loading content. In parallel, the dominant anatase component maintains its physico-chemical properties, without appreciable changes along the series of samples analyzed.

The performance of the samples was analyzed in terms of the activity and selectivity of the reaction under both UV and sunlight-type illumination conditions. The activity was measured through the calculation of the true quantum efficiency. An optimum of activity for all illumination conditions tested occurs for the $3 \mathrm{NiMo} / \mathrm{Ti}$ sample. The mentioned sample overperforms the bare titania references (parent anatase and P25) under all illumination conditions (factor of 1.4 and 2.0 for, respectively, the true quantum efficiency under UV and sunlight-type), indicating that the composite can be a good candidate for solar light photo-catalytic applications, particularly in the field of partial oxidation processes of hydrocarbons. On the other hand, the characterization study indicates that the optimum of activity occurs concomitantly to the alternation of the physico-chemical properties of the minor $\mathrm{NiMo}_{6}$ component and could be intimately related to the $\mathrm{NiMo}_{6}-\mathrm{TiO}_{2}$ interface performance under reaction conditions. An EPR study of the hydroxyl radical species indicates that the charge separation occurring at the composite system has a direct consequence on the formation of the radical species and commands the activity of the materials. The study thus presents a new, highly active, stable and selective photo-oxidation catalyst for benzaldehyde production from toluene.

\section{Acknowledgements}

Financial support from CSIC is fully tanked. G. B and C. I. C. would like to thank the following institutions for funding this work: CONICET; CICPBA and Universidad Nacional de La Plata, Argentina Projects. M.J.M.-B. thanks MINECO for the award of postdoctoral JdC contract (Ref. FJCI-2016-29014). E.R.C. thanks MINECO for grant CTQ201568951-C3-3-R and FEDER funds.

\section{Appendix A. Supplementary data}

Supplementary material related to this article can be found, in the online version, at doi: https://doi.org/10.1016/j.apcatb.2018.07.041.

\section{References}

[1] A. Kubacka, M. Fernández-García, G. Colón, Chem. Rev. 112 (2012) 1555-1614.

[2] J.C. Colmenares, R. Luque, Chem. Soc. Rev. 43 (2014) 765-778.

[3] M.T. Pope, A. Muller, Angew. Chem. Int. Ed. 30 (1991) 34-48.

[4] R. Sivakumar, J. Thomas, M.J. Yoon, J. Photochem. Photobiol. C 13 (2012) 277-298.

[5] Q. Zhang, Y. Tan, G. Liu, J. Zhanga, Y. Han, Green Chem. 16 (2014) 4708-4715.

[6] Y. Yang, Q. Wu, Y. Guo, C. Hu, E. Wang, J. Mol. Catal. A 225 (2005) 203-212.

[7] G. Marcí, E. López-García, L. Palmisano, Eur. J. Inorg. Chem. (2014) 21-35.

[8] K. Li, Y. Guo, F. Ma, H. Li, L. Chen, Y. Guo, Catal. Commun. 11 (2010) 839-843.

[9] Y. Tamasa, Catal. Surf. Asia 7 (2003) 203-217.

[10] S. Zhang, L. Chen, H. Liu, W. Guo, Y. Yang, Y. Guo, M. Huo, Chem. Eng. J. 200-202 (2012) 300-309.

[11] S.M. Verbruggen, J. Photochem. Photobiol. C 24 (2015) 4-82.

[12] M.J. Muñoz-Batista, M.N. Gómez-Cerezo, A. Kubacka, D. Tudela, M. FernándezGarcía, ACS Catal. 4 (2014) 63-72.

[13] Z. Yang, B. Chen, J. Zhao, Chem. Eng. Sci. 66 (2011) 5137-5147.

[14] M.J. Muñoz-Batista, A. Kubacka, A.B. Hungría, M. Fernández-García, J. Catal. 330 (2015) 154-166.

[15] I. Pettiti, I.L. Botto, C.I. Cabello, S. Colonna, M. Faticanti, G. Minelli, P. Porta H.J. Thomas, Appl. Catal. A 220 (2001) 113-121.

[16] C.I. Cabello, I.L. Botto, F. Cabrerizo, M. González, H. Thomas, Adsorpt. Sci. Technol. 18 (7) (2000) 591-599.

[17] A. Kubacka, M. Fernández-García, G. Colón, J. Catal. 254 (2008) 272-284.

[18] A. Le Bail, H. Duroy, J.L. Forquet, Mater. Res. Bull. 23 (1988) 447-452.

[19] A. Kubacka, G. Colón, M. Fernández-García, Appl. Catal. B 95 (2010) 238-244.

[20] S.E. Braslavsky, A.M. Braun, A.E. Cassano, A.V. Emeline, M.I. Litter, L. Palmisano, V.N. Parmon, N. Serpone, Pure Appl. Chem. 83 (2011) 931-1014.

[21] O.M. Alfano, D. Bahnemann, A.E. Cassano, R. Dillet, R. Golisch, Catal. Today 58 (2000) 199-230.

[22] M. Fernández-García, X. Wang, C. Belver, J.C. Hanson, J.A. Rodriguez, J. Phys. Chem. C 111 (2007) 674-682.

[23] N.I. Gumerova, N.A. Melnik, G.M. Rozantsev, V.N. Baumer, S.V. Radio, J. Struct. Chem. 56 (2015) 926-933.

[24] G. Bertolini, L.R. Pizzio, A. Kubacka, M. Muñoz-Batista, M. Fernández-García, Appl. Catal. B 225 (2018) 100-109.

[25] H. Yang, D. Zhang, L. Wang, Mater. Lett. 57 (2002) 674-678.

[26] Y. Xiao-Feng, W. Nian-Zu, H. Hui-Zhong, X. You-Chang, T. You-Qi, J. Mater. Chem. 11 (2001) 3337-3342.

[27] C.D. Wagner, W.M. Riggs, L.E. Davis, J.F. Moulder, G.E. Muilenber (Ed.), Handbook of X-Ray Photoemission Spectra, Perkin-Elmer, Minnesota, 1976.

[28] M. Ayala, E. Puello, P. Quintana, G. González-García, C. Díaz, RSC Adv. 5 (2015) $102652-11$

[29] M. Fernández-García, A. Martínez-Arias, J.C. Hanson, J.A. Rodríguez, Chem. Rev. 104 (2004) 4063-4105.

[30] S. Roy, D. Ganguli, J. Non-Cryst. Solids 151 (1992) 203-208.

[31] L. Boneviot, O. Legendre, M. Kermarec, D. Olivier, M. Che, J. Interfaces Colloid Sci. 134 (1990) 534-547.

[32] A.B.P. Lever, Inorganic Electronic Spectroscopy, Elsevier, Amsterdam, 1968.

[33] A. Kubacka, A. Fuerte, A. Martínez-Arias, M. Fernández-García, Appl. Catal. B 74 (2007) 26-33.

[34] J. Xu, R.O. Linborm, R.G. Temple, H.I. Mation, Ind. Eng. Chem. Proc. 4 (1965) 97-106. 
[35] C.G. Luo, Q. Liu, X.T. Wang, H. Hu, Appl. Catal. A 282 (2005) 55-59.

[36] U. Caudillo-Flores, M.J. Muñoz-Batista, F. Ung-Medina, G. Alonso-Núñez, A. Kubacka, J.A. Cortés, M. Fernández-García, Chem. Eng. J. 299 (2016) 393-402.

[37] M.J. Muñoz-Batista, U. Caudillo-Flores, F. Ung-Medina, M.C. Chávez-Parga, J.A. Cortés, A. Kubacka, M. Fernández-García, Appl. Catal. B 201 (2017) 400-410.

[38] G. Marcí, M. Addamo, V. Augugliaro, S. Coluccia, V. Loddo, G. Matra, L. Palmisano, M. Schiavello, J. Photochem. Photobiol. A 160 (2003) 105-114.

[39] T. Guo, Z. Dai, C. Wu, T. Zhu, Appl. Catal. B 79 (2008) 171-178.

[40] M. Sleiman, P. Conchon, C. Ferronato, J.-M. Chovelon, Appl. Catal. B 86 (2009) $159-165$.

[41] L. Zhong, J.J. Brancho, S. Batterman, B.M. Bartlett, C. Godwin, Appl. Catal. B 216 (2017) 122-132.

[42] O. Debono, V. Hequel, L. Le Coq, N. Locoge, F. Thevenet, Appl. Catal. B 218 (2017) 359-369.

[43] A. Hatipoglu, D. Vione, Y. Yalcin, C. Minero, Z. Cinar, J. Photobiol. Photochem. A 215 (2010) 59-68.

[44] Y. Zhang, G. Zhao, Y. Zhang, X. Huang, Green Chem. 16 (2014) 3860-3869.
[45] K. Cerdan, W. Ouyang, J.C. Colmenares, M.J. Muñoz-Batista, R. Luque, A.M. Balu, Chem. Eng. Sci. (2018), https://doi.org/10.1016/j.ces.2018.04.001.

[46] A. Magdziarz, J.C. Colmenares, O. Chernyayev, K. Kurzydłowski, J. Grzonka, ChemCatChem 8 (2016) 536-539.

[47] Y. Zheng, J. Liu, J. Liang, M. Jaroniec, S.Z. Qiao, Energy Environ. Sci. 5 (2012) 6717-6731.

[48] Y. Xu, M.A.A. Schoonen, Am. Miner. 85 (2000) 543-556.

[49] K.C. Christoforidis, A. Sengele, V. Keller, N. Keller, ACS Appl. Mater. Interfaces 7 (2015) 19324-19334.

[50] M.A. Grela, M.E.J. Coronel, A.J. Colussi, J. Phys. Chem. 100 (1996) 16940-16946.

[51] E.G. Janzen, N. Sankuratry, Y. Kotake, J. Magn. Reson. 111 (1996) 254-261.

[52] A. Kubacka, M.J. Muñoz-Batista, M. Ferrer, M. Fernández-García, Appl. Catal. B 140-141 (2013) 680-690.

[53] M.J. Muñoz-Batista, O. Fontelles-Carceller, M. Ferrer, M. Fernández-García, A. Kubacka, Appl. Catal. B Environ. 183 (2016) 86-95.

[54] D. Dvoranova', V. Brezova', M. Mazur, M.A. Malati, Appl. Catal. B 37 (2002) 91-105. 